\title{
Seed size variation: magnitude, distribution, and ecological correlates
}

\author{
HELEN J. MICHAELS ${ }^{a}$, B. BENNER ${ }^{b}$, A. P. HARTGERINK ${ }^{c}$, T. D. LEE ${ }^{c}$ and S. RICE \\ Department of Plant Biology, Morrill Hall, University of lllinois, 505 S. Goodwin, Urbana, IL 6180I, USA
}

\begin{abstract}
MARY F. WILLSON and ROBERT I. BERTIN ${ }^{d}$
Department of Ecology, Ethology, and Evolution, Shelford Vivarium, University of Illinois, 606 E. Healey St, Champaign, IL 61820, USA

Present addresses: a Division of Biological Sciences, University of Michigan, Ann Arbor, MI 48109; "Department of Botany, Indiana University, Bloomington, IN 47405; 'Department of Botany, University of New Hampshire, Durham, NH 03824; ${ }^{\mathrm{d} D e p a r t m e n t ~ o f ~ B i o l o g y, ~ C o l l e g e ~ o f ~ t h e ~ H o l y ~ C r o s s, ~ W o r c e s t e r, ~ M A ~ 01610, ~ U S A . ~}$
\end{abstract}

\section{Summary}

We examined seed-mass variation in 39 species (46 populations) of plants in eastern-central Illinois, USA. The coefficient of variation of seed mass commonly exceeded $20 \%$. Significant variation in mean seed mass occurred among conspecific plants in most species sampled (by hierarchical ANOVA), averaging $38 \%$ of total variance. For most species, within-plant variation was the larger component of total variance, averaging $62 \%$ of total variance. Variation in seed mass among fruits within crops was significant in most species tested.

We conclude that variation in seed mass among and within plants is widespread and common. There was little evidence of trade-offs between number of seeds and mean or variance of seed mass, and little correlational evidence of local competition for maternal resources. No consistent ecological (dispersal mode and growth form) correlates of variance of seed mass were evident.

Keywords: Seed size variation.

\section{Introduction}

Seed size (mass) can affect seed dispersal and seed predation, as well as seedling establishment, growth, and survival, and thus it has important ecological consequences (Howe and Richter, 1982; Fenner, 1983; Gross, 1984; Hendrix, 1984; Jordano, 1984; Mittelbach and Gross, 1984; Stanton, 1984a, 1985; Weller, 1985; and others). Mean seed sizes have been studied quite extensively, with emphasis on interspecific differences and environmental correlations (Salisbury, 1942; Baker, 1972) and relative intraspecific constancy (Harper et al., 1970). More recently, patterned phenotypic variation of seed mass with plant size (Hendrix, 1984), with season or fruit order (Cavers and Steel, 1984; Fuller et al., 1984; Hendrix, 1984), and with ovule position and parentage (Stanton, 1984b; Mazer et al., 1986) have been reported. However, we know rather little about the extent of variation in seed size, although several authors recently have called attention to its probable importance (Janzen, 1977a, 1977b, 1978, 1982a, 1982b; Capinera, 1979; Hendrix, 1984; Jordano, 1984; Temme, 1986; Thompson, 1984).

We examined several aspects of variation in seed mass. First, the variance was partitioned, to 


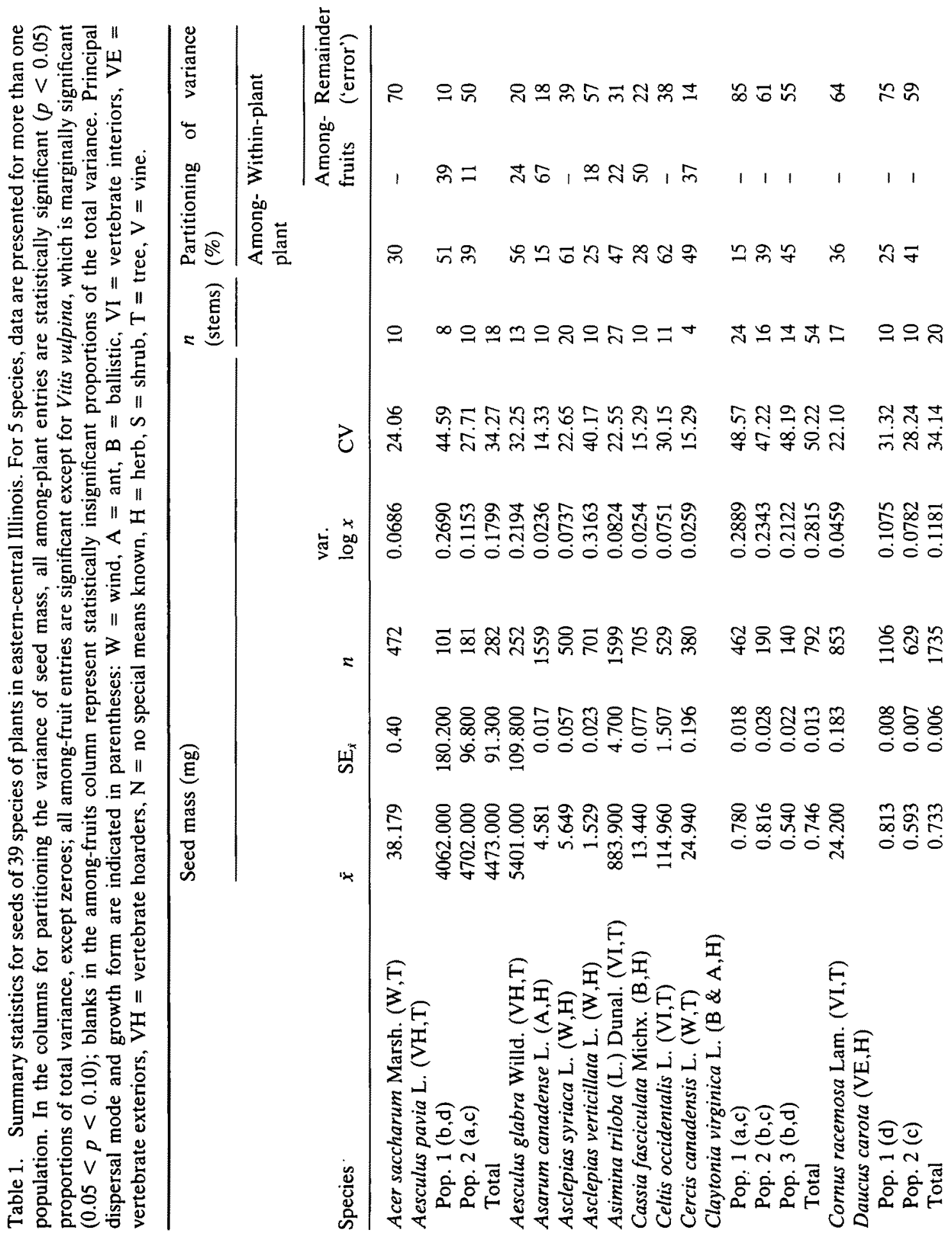




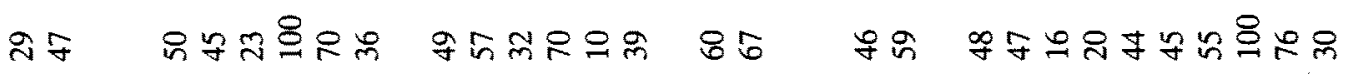

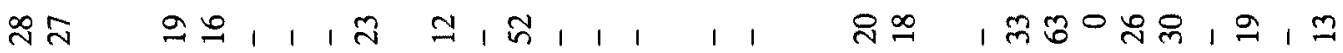

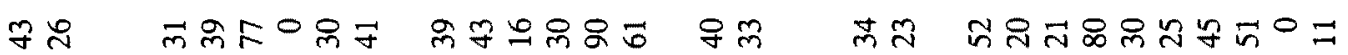

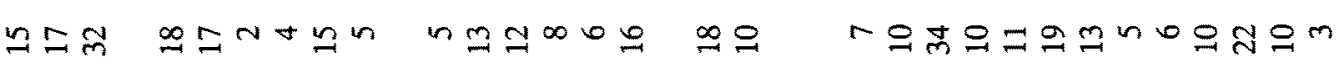

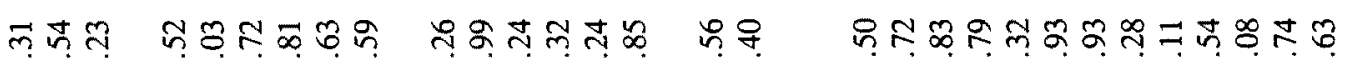

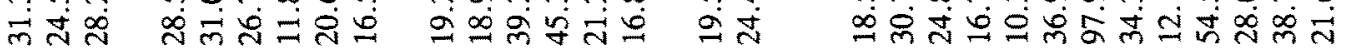

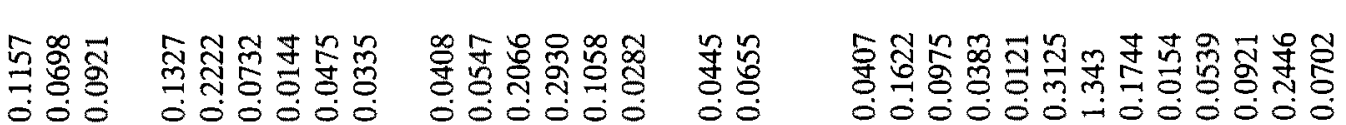

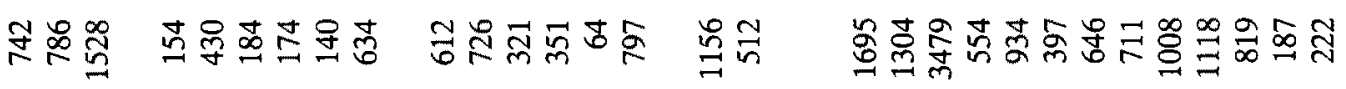

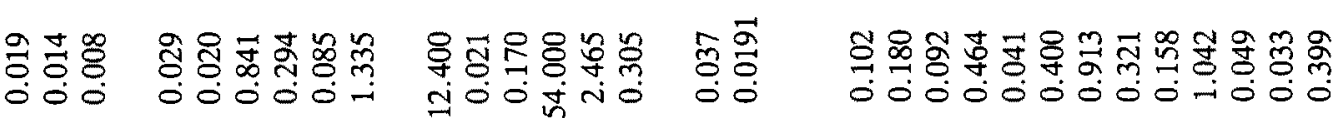

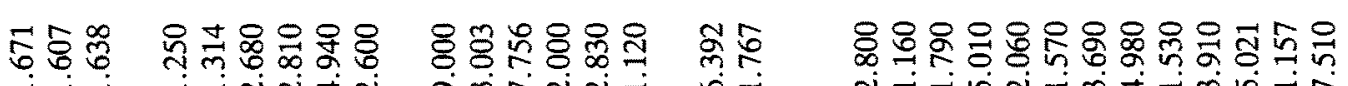

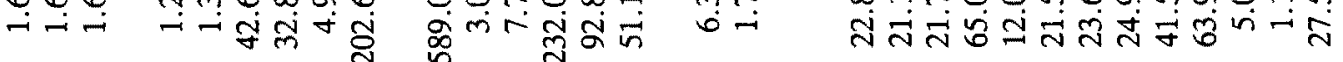

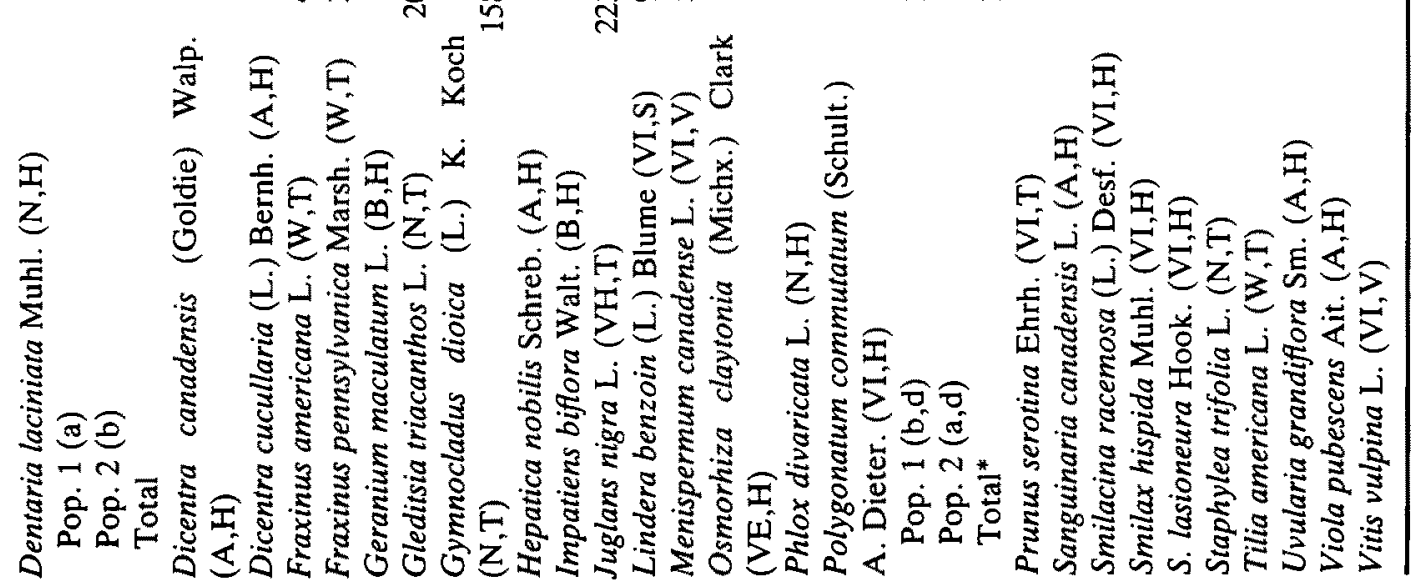


determine the magnitude and distribution of intraspecific variation in seed size for 39 species (46 populations):

(1) What is the magnitude of the variation?

(2) How is the variation distributed among and within the seed crops of conspecific plants?

(3) For species with multiseeded fruits, what is the distribution of variation among and within fruits from a given fruit crop?

Next, we examined (by correlation) several predictions about proximal causes of seed-size variation, particularly in relation to competition for maternal resources. If local competition among seeds for maternal resources is a proximate cause of variation in seed mass, several patterns of variation in both mean seed mass and its variance might be expected:

(1) Within a species, mean seed mass should be negatively correlated with total fruit crop size and with number of seeds per fruit (e.g. Smith and Fretwell, 1974), but the variance of seed mass should be positively correlated with crop size and number of seeds/fruit.

(2) The variance of seed mass should be smaller in those species with fruits having a large photosynthetic capacity (Bazzaz et al., 1979) available to contribute to the resources acquired by the enclosed seeds and thereby reducing within-fruit competition for resources.

(3) Plants growing in sunny habitats should have less variation in seed mass than conspecific plants growing in the shade.

(4) Seeds in late-maturing fruits should be at a competitive disadvantage to those in earlymaturing fruits within a fruit crop, and seed mass should decrease (and its variance increase) through the season.

Finally, we examined certain ecological factors for possible correlation with seed-size variation. If the variance (as well as the mean) of seed mass is ecologically important, as many authors (see earlier) have suggested, then we should expect the variance of seed mass to differ among species with differing ecologies. We examined seed-mass variances in our sample with respect to two simple ecological traits as a small start in a search for such patterns: (i) growth form, because growth form may be correlated with overall plant size or with ability to store resources and buffer effects of local variation in resources on seed size (see also Hamrick, 1979); and (ii) dispersal mode, because if variation in seed size affects variation in the seed shadow, then abiotic dispersal and autochory might select for greater variation in seed size than in seeds dispersed by fruiteating animals that behaviorally produce a variable seed shadow. Also, Salisbury (1942) noted that late-successional species tend to have larger seeds than early-successional species, in association with the greater difficulties of establishment in late succession. The same advantages of larger seeds in later seral stages should hold among populations within a species, although gene flow and/or developmental constraints may prevent a divergence of seed size among conspecific populations. We examined three species for successional trends in mean seed mass.

\section{Materials and methods}

Mature seeds and fruits for all but one species (Aesculus pavia, collected in Missouri; see Bertin, 1982 ) in this survey were collected in autumn 1979 or spring/summer 1980 in Champaign and Vermilion Counties, in eastern-central Illinois (approximately $40^{\circ} \mathrm{N}, 88^{\circ} \mathrm{W}$ ). Whenever possible, the entire fruit production (or 'crop') of a plant was collected. For those species with very large friut crops, sampling was distributed as evenly as possible over a whole plant or arbitrarily, when dispersal units were harvested from the ground beneath a parent plant (Ulmus, Acer, some Tilia) and when only one fruit per stem was collected (Asclepias syriaca). Most species were collected 
within $5 \mathrm{~km}$ of Urbana, IL, chiefly in Trelease Woods and the adjacent Phillips Tract (an oldfield) $5 \mathrm{~km}$ north-east of Urbana. Other species were collected as follows. Cercis, Claytonia, Sanguinaria and Fraxinus americana (full names and authorities are given in Table 1) were harvested in and about Kickapoo State Park, $13 \mathrm{~km}$ west of Danville, IL. Hepatica was collected at the Vermilion River Observatory, about $12 \mathrm{~km}$ south-east of Danville. Staphylea crops were sampled at Forest Glen County Preserve, $8 \mathrm{~km}$ south-east of Westville, IL. Fraxinus americana was collected from the banks of Stony Creek, a tributary of the Salt Fork of the Vermilion River, between Urbana and Danville. Cornus fruits were harvested at Homer Lake, about $3 \mathrm{~km}$ northwest of Homer, IL, and at Trelease. Tilia fruits were collected at Trelease and south of Oakwood, Vermilion County. Juglans collections were made in Urbana, at Homer Lake, and near Mahomet, IL. Many species in our sample are not known to be clonal; for other species, collections were made from ramets ('stems' in Table 1) usually well separated in space and subjectively judged to be physiologically independent plants.

The seeds of wind-dispersed species (marked ' $W$ ' in Table 1) were allowed to air-dry to a constant mass at room temperature; because these seeds naturally disperse in an air-dried state, air-dry weights were measured. All other seeds, in which dry weights were not predictably related to dispersal, were oven-dried to a constant mass at $60-70^{\circ} \mathrm{C}$ to assess maternal investment. Associated structures (capsules, bracts, wings, pappi, edible pulp, or husks) were separated from the seeds whenever possible. For Fraxinus spp., Daucus, Osmorhiza and Hepatica, the mass of the entire dispersal unit was recorded as seed mass because the dispersal structures were not separable from the seeds. For Tilia the hard spherical fruit was weighed (not the seed itself). For Impatiens, only seeds of chasmogamous flowers were harvested. All 'seeds' were weighed separately to at least three significant digits over the range of seed mass of each species. When fruits contained more than 25 seeds, an arbitrary subsample of 25 seeds or $10 \%$ of the seeds in that fruit (whichever was larger) was taken. Plots of the variance versus seed number were used to further determine the level of subsampling required to stabilize the variance. We subjectively excluded seeds that were likely to be inviable (unusually small seeds that contained abnormallooking embryos or that appeared hollow).

For contrasts of seed-size variation in different habitats, the following habitat definitions were used:

(1) 'Shade' refers to populations growing in forest interior, 'sun' refers to populations growing in the open or at the edge of a woodlot.

(2) Early successional habitats for Claytonia and Aesculus pavia were fields, later successional habitats were forests; for Daucus, successional status refers to oldfields of differing ages. Photosynthetic capacity of the fruit was derived in two ways: (i) from published values (e.g. Bazzaz et al., 1979), supplemented by a few unpublished values ( $R$. Carlson, pers. comm.); and (ii) from estimates of fruit shape (surface/volume ratio), which is correlated with photosynthetic ability of fruit (op. cit.) - round, large fruits have lower surface/volume ratios and lower relative photosynthetic ability than do flat, small fruits. For comparisons using method (ii), only fruits at the extremes of the surface/volume ratio spectrum were used; species with fruits of intermediate shape/sizes were omitted.

The coefficient of variation $(\mathrm{CV}=$ standard deviation/mean $\times 100)$ was used for most ecological comparisons of the magnitude of variation, and most comparisons were made using non-parametric statistics. Some controversy exists concerning the appropriate statistical method for comparing variation (e.g. Lande, 1977; Van Valen, 1978; Sokal and Braumann, 1980). Therefore, non-parametric testing of CVs was adopted as a conservative method of analysis of most of the data. Parametric tests of log-transformed data (Lewontin, 1966) were used only for 
within-crop correlations of mean and variance of seed weight with seed number per fruit. The $5 \%$ significance level was used in all statistical decisions, except as otherwise noted. We present results of marginal significance $(0.05<p<0.10)$ where they support well-established trends.

\section{Results}

Seed mass: magnitude and partitioning of the variance

The species surveyed are listed in Table 1 , with some summary statistics at the population and species levels. The coefficient of variation of seed mass (mass per seed) exceeded $20 \%$ in most species and populations surveyed (Table 1) and was greater than $10 \%$ in all cases, although none exceeded $100 \%$. The mean $\mathrm{CV}$ for our 39 species was about $28 \%$.

A hierarchical ANOVA (Zar, 1984) on the data for each population was used to assess the percentage of the total variance in seed mass that was contributed by variation among plants within populations. For species with multiseeded fruits, the ANOVA assessed variation among fruits within fruit crops and among seed within fruits.

For 37 of 39 species, among-plant variation in seed mass was statistically significant; its contribution to total variance ranged from 11 to $90 \%$ (Table 1); the average among-plant variance for all 46 populations was $38 \%$ of the total. Variation among plants was particularly large ( $>75 \%$ of total variance) in Fraxinus americana (but $n=2$ trees only), Lindera and Smilax hispida; in addition, among-plant variation comprised $>50 \%$ of the total in Aesculus pavia (one population), A. glabra, Asclepias syriaca, Celtis, Menispermum, Prunus and Uvularia. None of the total variance was due to among-plant variation in Viola and Fraxinus pennsylvanica, while in Vitis, Asarum and Claytonia populations this component of variance was also very low.

In 29 species and one population of Aesculus pavia, within-plant variation was the larger component of total variance. Within-plant variance ranged from 10 to $100 \%$ of the total variance; the average was $62 \%$ of the total variance. Among-fruit variance was statistically significant by the hierarchical ANOVA for 22 of the 24 testable species; this component in Vitis was marginally significant. For Smilax hispida, among-fruit variance contributed nothing to total variance, perhaps chiefly because multiseededness was very rare. This component of variance was particularly high ( $>50 \%$ of the total) in Asarum, Cassia, Impatiens and Smilacina.

\section{Proximate causes}

Correlates with mean seed mass (within species). Mean seed mass was not correlated with size of the fruit crop per ramet in most of the 12 species for which whole crops were collected (Claytonia, Dicentra spp., Geranium, Hepatica, Phlox, Osmorhiza, Polygonatum, Sanguinaria, Smilacina, Uvularia). The sole exception was for the shaded sample of Dentaria in which there was a significant negative correlation between mean seed mass and number of fruits per stem (Kendall's tau $=-0.16)$.

At the level of single fruits (in species with $>1$ seed/fruit), mean seed mass was not significantly correlated, either positively or negatively, with the number of seeds per fruit for most plants sampled (21 species were tested, all those with at least two plants with variable seed numbers/ fruit, Pearson product-moment correlation). The exceptions were Asarum ( 7 of 10 plants showed a significant negative correlation) and Staphylea (5 of 6 plants showed a significant positive correlation).

For Dentaria, the order of fruit production through the season was recorded for each ramet. For the shaded population there was a significant negative correlation of mean seed mass and the order in which fruits developed (Kendall's tau $=0.18$ ). 
Correlates with variation in seed mass. Variation in seed mass was not correlated with size of the fruit crop per ramet (Spearman rank correlation) within any of the 12 species for which whole crops were collected, nor with fruit order in Dentaria.

For Smilacina $(n=16)$ and Phlox $(n=14)$ seeds from single-seeded fruits had a significantly higher mean CV of seed mass than did seeds from multiseeded fruits in the same crop; Wilcoxonmatched pairs test, normal approximation, $z=-2.13, z=-3.03$, respectively). For six other species whose fruits varied in number of seeds per fruit, however, there was no significant withincrop difference in variation in mass of seeds from single-seeded and multiseeded fruits.

Seeds from shade-grown plants were significantly more variable than those from sun-grown plants only in Polygonatum (sun 17.9, $n=7$ stems; shade 24.9, $n=10$; Kruskal-Wallis test), in which the average number of seeds/plant was also smaller in the shade (sun 177.5, shade 130.4, $t$-test). However, no consistent differences were found for Dentaria, Claytonia or Aesculus pavia.

Variation in seed mass was not correlated with the photosynthetic contribution of the fruit in the six species for which photosynthesis data were available. However, those species with fruits with high surface to volume ratios (and high expected photosynthetic capacity) had significantly lower mean CVs $(n=8, \bar{x}=17.64)$ than those with low surface/volume ratios $(n=9, \bar{x}=30.93$; Wilcoxon 2-sample test, $p=0.01$ ).

\section{Ecological correlates}

Variation in seed mass was not detectably related to growth form or dispersal mode (KruskalWallis test; Table 1).

We examined three species for between-population differences in mean seed mass in relation to seral stage. For Aesculus pavia, there was no significant difference between seral stage (field and forest; Wilcoxon test). Mean seed mass of late-successional plants of Daucus was significantly greater than for early-successional plants (late, $\bar{x}=0.79 \mathrm{mg}$; early, $\bar{x}=0.55 \mathrm{mg}$; both $n=$ $10, p<0.01$, Wilcoxon test). However, mean seed mass of Claytonia was greater in an earlysuccessional site than in a later stage (early, $\bar{x}=0.71 \mathrm{mg}, n=16$; late, $\bar{x}=0.47 \mathrm{mg}, n=14 ; p<$ 0.01 , Wilcoxon test).

\section{Discussion}

\section{Magnitude of variation in seed mass}

Thompson (1984) noted that CVs over 5\% are often considered 'large' in biological systems and reported seed-size CVs of $14-250 \%$ from the literature. By the $5 \%$ criterion, all of our 39 species exhibit 'large' CVs, indicating that within-species variation in seed size is considerable.

The review by Harper et al. (1970) is frequently cited as evidence of the general constancy of seed weight within species, but this is an erroneous interpretation of their discussion, which dwells on the relative constancy of mean seed weight within species. Harper et al. (1970) discuss genetic variation among plants in seed size, the results of natural and artificial selection for seed size, as well as both maternal and paternal effects on seed size see (Vander Kloet and Tosh (1984) and Mazer et al. (1986) for recent examples of paternal effects). Moreover, other work by Harper's group on Linum usitatissimum L. has demonstrated that density influenced the pattern of variation of seed weights (Obeid et al., 1967). Yet somehow this part of their message became overshadowed by other conclusions. 


\section{Distribution of variation in seed mass}

Significant among-plant variation in seed mass was found in 37 of 39 species examined. The among-plant component of variance was larger than the within-plant component in at least one population of 10 species; the within-plant component was larger in the remainder. Of the 24 species with variable numbers of seeds per fruit, the among-fruit variance was significant for 22 species. Thus, for most of the species examined, maternal parents were producing highly variable offspring and, in most species, parents differed in the size distribution of offspring. These differences among parents are likely to have both genetic and environmental components. For example, parents may differ in levels of plasticity of resource allocation, genetically-based maternal effects on offspring size, or resource levels due to resource distribution patterns.

\section{Proximate causes}

We found little evidence of trade-offs between mean seed mass and seed numbers within fruits or within whole seed crops. The principal exception was the shaded population of Dentaria, which exhibited a negative correlation of mean seed mass with number of fruits per stem and with fruit order. The failure to detect evidence of trade-offs in most cases may be partially attributable to the effects of plant size, which may have such strong effects on seed number that trade-offs may be evident only when confounding effects of maternal size variation are removed. The simplicity of the trade-off concept has made it very popular in consideration of the evolution of life histories (e.g. Smith and Fretwell, 1974) and examples have been found in some instances (e.g. among plants of Silene alba, D. Hanych, pers. comm.). However, it is apparent now that simplistic trade-offs between size and number are often not found (see also Primack, 1978; Hardin, 1984). This does not mean, necessarily, that trade-offs are not important, but it does mean that the scale or conditions in which they may occur need to be examined more thoroughly.

Variation in seed mass was not consistently related (within species) to fruit-crop size, numbers of seeds/fruit, or shadiness of habitat. Although variation in seed mass among species was not correlated with the actual photosynthetic contribution of the fruits, species with fruits with high expected photosynthetic capacity had reduced variation in seed mass. If fruit shape (surface to volume ratio) generally influences fruit photosynthetic capacity and resources available to developing seeds, then variation in seed mass may also be relatively low in other species with high surface to volume ratios.

Thus, if local competition for maternal resources influences seed size, in most cases the effect seems to be small and/or masked by other factors. There may also be strong developmental constraints on seed size, both among related species (Primack, in press) and among plants. Other proximate causes of within-crop variance in seed size are time of fertilization and/or temporal variation in resources available for seed provisioning or the range of offspring quality among seeds (Cavers and Steel, 1984; Fuller et al., 1983; Hendrix, 1984; Thompson, 1984; Stanton, 1984b; Mazer et al., 1986; Temme, 1986).

\section{Ecological correlates}

Growth form, dispersal mode, and successional stage were not generally correlated with variation in seed size. If the variance of seed size (and not just the mean) is ecologically important and subject to natural selection, it is likely that ecological patterns in the magnitude of variation occur, because selection for variation would be stronger in some species than in others. Species may differ in their constraints on degree of variation imposed by selection for different levels of plasticity (Marshall et al., 1985), or in allocational priorities among intercorrelated yield components (e.g. optimal seed size may be highly canalized in some species, while seed number is 
constrained in others). Finally, if genetic variation in offspring quality within species contributes to size variation (Temme, 1986), then differences in breeding system may be a source of interspecific differences in the magnitude of seed-size variation. Although we have not identified clear general ecological patterns in the magnitude of variation, further examination of this possibility should be encouraged.

\section{General comment}

Many comparisons of the variation in mean seed weight are made with seed numbers or other features often closely associated with plant size (Harper et al., 1970; Obeid et al., 1967). It might be useful to quantify the comparison of variation in seed size and seed number and determine if there are any cases in which seed-size variation is greater than that of seed number. Moreover, few comparisons have been made of the variance of seed weights and the variances of other morphological features. It might be useful to know if seed size is more or less variable than some morphological features that are not related to plant size, which is notoriously variable. For both comparisons, quantitative assessment of the degree of variation is needed.

The existence of within- and among-plant variation in seed size has been known at least since Salisbury (1942). Our results, and those of others cited, show that seed-size variation is both large and common. Variation in seed size is likely to affect the length and density of the seed and seedling shadows around a parent plant, by changing dispersal distances, by altering the range of usable safe sites, or perhaps by determining the outcome of competition among siblings (B. Wallace, pers. comm.) and with other plants. The ecological consequences of differences in seedsize variance need to be determined experimentally and deserve much further exploration.

\section{Acknowledgments}

We are grateful to S. E. Franson and A. W. Ghent for statistical consultation, and to D. Stanton, C. Smythe, D. Hartnett, R. Guffey and K. Schwaegerle who participated in earlier phases of the study. C. K. Augspurger, C. A. Kelly, D. Thiede, J. N. Thompson and L. M. Wolfe made helpful comments on the manuscript.

\section{References}

Baker, H. G. (1972) Seed weight in relation to environmental conditions in California. Ecology 53, 997-1010.

Bazzaz, F. A., Carlson, R. W. and Harper, J. L. (1979) Contribution to reproductive effort by photosynthesis of flowers and fruits. Nature 279, 554-5.

Bertin, R. I. (1982) The ecology of sex expression in red buckeye. Ecology 63, 445-56.

Capinera, J. L. (1979) Qualitative variation in plants and insects: effect of propagule size on ecological plasticity. Amer. Natur. 114, 350-61.

Cavers, P. B. and Steel, M. G. (1984) Patterns of change in seed weight over time on individual plants. Amer. Natur. 124, 324-35.

Fenner, M. (1983) Relationships between seed weight, ash content and seedling growth in twenty-four species of Compositae. New Phytol. 95, 697-706.

Fuller, W., Hance, C. E. and Hutchings, M. J. (1983) Within-season fluctuations in mean fruit weight in Leontodon hispidus L. Annals Bot. 51, 545-9.

Gross, K. L. (1984) Effects of seed size and growth form on seedling establishment of six monocarpic perennial plants. J. Ecol. 72, 369-87.

Hamrick, J. L. (1979) Genetic variation and longevity. In Topics in Plant Population Biology (O. T. Solbrig, S. Jain, G. B. Johnson and P. H. Raven, eds) pp. 84-113. Columbia University Press, New York, USA. 
Hardin, E. D. (1984) Variation in seed weight, number per capsule and germination in Populus deltoides Bartr. trees in southeastern Ohio. Amer. Midl. Natur. 112, 29-34.

Harper, J. L., Lovell, P. H. and Moore, K. G. (1970) The shapes and sizes of seeds. Ann. Rev. Ecol. Syst. 1, 327-56.

Hendrix, S. D. (1984) Variation in seed weight and its effect on germination in Pastinaca sativa L. (Umbelliferae). Amer. J. Bot. 71, 795-802.

Howe, H. F. and Richter, W. M. (1982) Effects of seed size on seedling size in Virola surinamensis: a within and between tree analysis. Oecologia 53, 347-51.

Janzen, D. H. (1977a) Variation in seed size within a crop of a Costa Rican Mucuna andreana (Leguminosae). Amer. J. Bot. 64, 347-9.

Janzen, D. H. (1977b) Variation in seed weight in Costa Rican Cassia grandis (Leguminosae). Trop. Ecol. $18,117-86$.

Janzen, D. H. (1978) Inter- and intra-crop variation in seed weight of Costa Rican Ateleia herbert-smithii Pitt. (Leguminosae). Brenesia 14/15, 311-23.

Janzen, D. H. (1982a) Variation in average seed size and fruit readiness in a fruit crop of a guanacaste tree (Leguminosae: Enterolobium cyclocarpum). Amer. J. Bot. 69, 1169-78.

Janzen, D. H. (1982b) Weight of seeds in 1-3-seeded fruits of Lonchocarpus costaricensis (Leguminosae), a Costa Rican wind-dispersed tree. Brenesia 19/20, 363-8.

Jordano, P. (1984) Seed weight variation and differential avian dispersal in blackberries Rubus ulmifolius. Oikos 43, 149-53.

Lande, R. (1977) On comparing coefficients of variability. Syst. Zool. 26, 214-17.

Lewontin, R. C. (1966) On the measurement of relative variability. Syst. Zool. 15, 141-2.

Marshall, D. L., Fowler, N. L. and Levin, D. A. (1985) Plasticity in yield components in natural populations of three species of Sesbania. Ecology 66, 753-61.

Mazer, S. J., Snow, A. A. and Stanton, M. L. (1986) Fertilization dynamics and parental effects upon fruit development in Raphanus raphanistrum: consquences for seed size variation. Amer. J. Bot. 73, 500-11.

Mittelbach, G. and Gross, K. L. (1984) Experimental studies of seed predation in old-fields. Oecologia 65 , 7-13.

Obeid, M., Machin, D. and Harper, J. L. (1967) Influence of density on plant to plant variation in fiber flax (Linum usitatissimum L.) Crop Sci. 7, 471-3.

Primack, R. B. (1978) Regulation of seed yield in Plantago. J. Ecol. 66, 835-47.

Primack, R. B. Relationships among flowers, fruits, and seeds. Ann. Rev. Ecol. Syst. 16 (in press).

Salisbury, E. J. (1942) The Reproductive Capacity of Plants. Bell, London, UK.

Smith, C. C. and Fretwell, S. (1974) The optimal balance between size and number of offspring. Amer. Natur. 108, 499-506.

Sokal, R. R. and Braumann, C. A. (1980) Significance tests for coefficients of variation and variability profiles. Syst. Zool. 29, 50-66.

Stanton, M. L. (1984a) Seed variation in wild radish: effect of seed size on components of seedling and adult fitness. Ecology 65, 1105-12.

Stanton, M. L. (1984b) Developmental and genetic sources of seed weight variation in Raphanus raphanistrum L. (Brassicaceae). Amer. J. Bot. 71, 1090-8.

Stanton, M. L. (1985) Seed size and emergence time within a stand of wild radish (Raphanus raphanistrum L.): the establishment of a fitness hierarchy. Oecologia 67, 524-31.

Temme, D. H. (1986) Seed size variability: a consequence of variable genetic quality among offspring? Evolution 40, 414-17.

Thompson, J. N. (1984) Variation among individual seed masses in Lomatium grayi (Umbelliferae) under controlled conditions: magnitude and partitioning of the variance. Ecology 65, 626-31.

Vander Kloet, S. P. and Tosh, D. (1984) Effects of pollen donors on seed production, seed weight, germination and seedling vigor in Vaccinium corymbosum L. Amer. Midl. Natur, 112, 392-6.

Van Valen, L. (1978) The statistics of variation. Evol. Theory 4, 33-43.

Weller, S. G. (1985) Establishment of Lithospermum caroliniense on sand dunes: the role of nutlet mass. Ecology 66, 1893-901.

Zar, J. H. (1984) Biostatistical Analysis (2nd edn). Prentice-Hall, Englewood Cliffs, NJ, USA. 